\title{
Effect of supplementary implantation of a sulcus- fixated intraocular lens in patients with negative dysphotopsia
}

Citation for published version (APA):

Makhotkina, N. Y., Dugrain, V., Purchase, D., Berendschot, T. T. J. M., \& Nuijts, R. M. M. A. (2018). Effect of supplementary implantation of a sulcus-fixated intraocular lens in patients with negative dysphotopsia. Journal of Cataract and Refractive Surgery, 44(2), 209-218. https://doi.org/10.1016/j.jcrs.2017.11.013

Document status and date:

Published: 01/02/2018

DOI:

10.1016/j.jcrs.2017.11.013

Document Version:

Publisher's PDF, also known as Version of record

\section{Document license:}

Taverne

Please check the document version of this publication:

- A submitted manuscript is the version of the article upon submission and before peer-review. There can be important differences between the submitted version and the official published version of record.

People interested in the research are advised to contact the author for the final version of the publication, or visit the DOI to the publisher's website.

- The final author version and the galley proof are versions of the publication after peer review.

- The final published version features the final layout of the paper including the volume, issue and page numbers.

Link to publication

\footnotetext{
General rights rights.

- You may freely distribute the URL identifying the publication in the public portal. please follow below link for the End User Agreement:

www.umlib.nl/taverne-license

Take down policy

If you believe that this document breaches copyright please contact us at:

repository@maastrichtuniversity.nl

providing details and we will investigate your claim.
}

Copyright and moral rights for the publications made accessible in the public portal are retained by the authors and/or other copyright owners and it is a condition of accessing publications that users recognise and abide by the legal requirements associated with these

- Users may download and print one copy of any publication from the public portal for the purpose of private study or research.

- You may not further distribute the material or use it for any profit-making activity or commercial gain

If the publication is distributed under the terms of Article $25 \mathrm{fa}$ of the Dutch Copyright Act, indicated by the "Taverne" license above, 


\title{
Effect of supplementary implantation of a sulcus-fixated intraocular lens in patients with negative dysphotopsia
}

\author{
Natalia Y. Makhotkina, MD, Vincent Dugrain, PhD, Daniel Purchase, EngD, Tos T.J.M. Berendschot, PhD, \\ Rudy M.M.A. Nuijts, $M D, P h D$
}

Purpose: To evaluate whether the outcome of negative dysphotopsia treatment by implantation of a Sulcoflex intraocular lens (IOL) can be understood using individual biometry and optical modeling data.

Setting: University Eye Clinic, Maastricht University Medical Centre, Maastricht, the Netherlands.

\section{Design: Retrospective case series.}

Methods: Patients with negative dysphotopsia were treated with supplementary implantation of a sulcus-fixated IOL. Preoperative and postoperative ray-tracing optical models of eyes with negative dysphotopsia were constructed in the Zemax Optic Studio program using individual biometric data. The relationship between biometric parameters, ray-tracing data, and the course of negative dysphotopsia was evaluated.

Results: The study comprised 8 patients (10 eyes). After surgery, negative dysphotopsia resolved completely in 6 eyes, partially in 2 eyes, and persisted in 2 eyes. There was no relationship between the course of negative dysphotopsia and age, IOL power, or individual biometry results other than a larger angle $\kappa$ that was observed in 2 patients with persistent negative dysphotopsia after surgery. Preoperative ray-tracing models showed a decrease in light irradiance at the periphery relative to the center of visual field. After sulcus-fixated IOL implantation, this decrease partially resolved, in particular, for a small pupil aperture $(P<.05)$, and it was more prominent in patients in whom negative dysphotopsia resolved completely than in those with partial or persistent negative dysphotopsia $(P=.065$ at $1.5 \mathrm{~mm}$ aperture).

Conclusions: Of all individual biometry results, only angle $\kappa$ showed a relationship with the course of negative dysphotopsia. In patient-specific optical modeling of sulcus-fixated IOL implantation, the increase in simulated light irradiance at the periphery was related to the course of negative dysphotopsia.

J Cataract Refract Surg 2018; 44:209-218 @ 2018 ASCRS and ESCRS

므 Supplemental material available at www.jcrsjournal.org.
$\mathrm{T}$ he term "negative dysphotopsia" was originally introduced in 2000 by Davison, ${ }^{1}$ who described complaints of "a subjective darkness of a shadow, which can be arc-shaped, usually in the temporal field of vision" in patients after uneventful cataract surgery.

The symptoms are usually worse in photopic conditions $^{2-5}$ and might be alleviated by pupil dilatation. ${ }^{2}$ Many case reports and clinical and laboratory studies have evaluated potential mechanisms of negative dysphotopsia over the past 15 years. ${ }^{6}$

The last most comprehensive laboratory study pointed out primary and secondary factors that increase the risk for negative dysphotopsia, ${ }^{7}$ and its results are partially supported by previous clinical studies (Table $1^{2-5,8-16}$ ). The current opinion that negative dysphotopsia is a result of a complex interaction between intraocular lens (IOL) optics and an anatomically predisposed eye suggests the multifactorial nature of this phenomenon.

The primary accepted treatment strategy is a combination of counseling and reassurance because most cases of negative dysphotopsia will likely abate. It has been suggested that negative dysphotopsia can abate because of neuroadaptation or early postoperative changes, such as opacification of the peripheral lens capsule. ${ }^{14,20-23}$ Severe persistent cases can be treated with IOL exchange with placement of a secondary IOL in the bag or in the ciliary sulcus, implantation of a supplementary IOL, reverse optic capture, or neodymium:YAG (Nd:YAG) anterior 


\begin{tabular}{|c|c|}
\hline Causative Factor & $\begin{array}{l}\text { Supported Clinical } \\
\text { Study Reference }\end{array}$ \\
\hline \multicolumn{2}{|l|}{ Primary } \\
\hline Smaller photopic pupil & $2-5$ \\
\hline Larger positive angle $\kappa$ & - \\
\hline $\begin{array}{l}\text { Shape of IOL (with steeper } \\
\text { posterior surface) }\end{array}$ & - \\
\hline $\begin{array}{l}\text { Shorter axial distance of } \\
\text { IOL behind iris }\end{array}$ & * \\
\hline $\begin{array}{l}\text { Nasal anterior capsule overlying } \\
\text { anterior nasal IOL }\end{array}$ & $2,8,9$ \\
\hline $\begin{array}{l}\text { Higher dioptric power if } \\
\text { equi-biconvex or plano-convex } \\
\text { IOL }\end{array}$ & 10,11 \\
\hline $\begin{array}{l}\text { Optic-haptic junction of IOL } \\
\text { not horizontal }\end{array}$ & 12 \\
\hline \multicolumn{2}{|l|}{ Secondary } \\
\hline $\begin{array}{l}\text { Edge design (truncated vs. } \\
\text { rounded and thickness) }\end{array}$ & $3,10,13,14$ \\
\hline $\begin{array}{l}\text { Material of IOL (higher versus } \\
\text { lower index) }\end{array}$ & $12,14,15$ \\
\hline Negative aspheric surfaces & - \\
\hline
\end{tabular}

$\mathrm{IOL}=$ intraocular lens

${ }^{*}$ Two clinical studies ${ }^{3,16}$ suggested a longer axial distance of the $\mathrm{OL}$ behind the iris as a possible causative factor

capsulectomy. Until recently, IOL exchange with implantation of a secondary IOL in the ciliary sulcus seemed to be most successful for the resolution of negative dysphotopsia, whereas other treatment modalities have had lower degrees of success. ${ }^{1,2,8-10,24-26}$

Patients with severe negative dysphotopsia at the University Eye Clinic Maastricht are treated with supplementary implantation of a sulcus-fixated IOL (Sulcoflex, Rayner Intraocular Lenses, Ltd.) in the ciliary sulcus, which is a safe procedure leading to improvement or resolution of negative dysphotopsia in $78 \%$ of cases. ${ }^{25}$ However, surgical outcomes cannot be predicted because the pathophysiological mechanism of the treatment effect of the sulcus-fixated IOL is still unclear.

In this study, we evaluated the relationship between clinical data and surgical outcomes of patients with bothersome negative dysphotopsia treated with implantation of the sulcus-fixated IOL to identify factors that contribute to the resolution or persistence of negative dysphotopsia after surgery. In addition, to account for the multifactorial nature of negative dysphotopsia, we assessed the combined effect of different factors using optical modeling of individual biometric data before and after implantation of the sulcus-fixated IOL. Optical simulation of a piggyback IOL suggested the role of multiple surface reflections in the resolution of negative dysphotopsia. ${ }^{23}$ However, this analysis was based on a general eye model and could not explain partial improvement or persistence of the symptoms in different cases. To our knowledge, the modeling of negative dysphotopsia in a systematic fashion with patient-specific data has not yet been performed.

\section{PATIENTS AND METHODS}

\section{Clinical Data}

Medical files of patients with severe negative dysphotopsia who had supplementary implantation of a sulcus-fixated IOL between March 2014 and June 2016 were retrospectively reviewed. The data were partially reported previously. ${ }^{25}$ All patients had uneventful phacoemulsification with IOL implantation in the capsular bag. Secondary implantations were performed by an experienced surgeon (R.N.) at the University Eye Clinic in Maastricht, the Netherlands. A supplementary IOL was implanted in the ciliary sulcus, anterior to the primary IOL-capsular bag complex. A sulcus-fixated IOL (Sulcoflex aspheric 653L in 9 eyes and Sulcoflex aspheric toric $653 \mathrm{~T}$ in 1 eye) with powers varying from 0 to 0.5 diopter (D) was used in all cases. The use of retrospective clinical data is in line with the guidelines of the Medical Ethical Committee of Maastricht University Medical Center.

Patient evaluations were performed preoperatively and 1 month after surgery. The evaluations included uncorrected and corrected distance visual acuities (Snellen), manifest refraction, Goldmann applanation tonometry, slitlamp evaluation, Scheimpflug photography (Pentacam, Oculus Optikgeräte $\mathrm{GmbH}$ ), anterior segment optical coherence tomography (AS-OCT) (SS-1000, Tomey Corp.), partial coherence interferometry (PCI) (IOLMaster, Carl Zeiss Meditec AG), and kinetic perimetry (Goldmann perimeter, Haag-Streit AG). Kinetic perimetry was performed in photopic conditions with stimuli of maximum size and intensity (V4e) to evaluate the extension of the peripheral visual field and/or a presence of the relative scotoma as it was previously described. ${ }^{11}$ Data from Scheimpflug photography, AS-OCT, and kinetic perimetry were used in the current study. The chord $\mu$ (ie, approximation of angle $\kappa$, the angle between the apex [visual axis] and the pupil center) was assessed using the Holladay report on the Scheimpflug photography device. ${ }^{A}$

\section{Optical Modeling of Light Distribution on the Retina}

Biometric measurements of the patients were used for the construction of ray-tracing models. Anterior chamber depth, cornea-iris distance, thickness of the iris, thickness of the primary and supplementary IOLs, and distance between primary and supplementary IOLs were measured with AS-OCT. Because the AS-OCT software uses the refractive index of the aqueous humor of 1.343 for calculation of the IOL thicknesses and thus overestimates it, the measured IOL thicknesses were adjusted for the differences in the refractive indexes between aqueous humor and the IOL. The axial length (AL) of the eyes was measured with PCI.

Patient-specific optical models of the eyes were built in Zemax Optic Studio Optical Simulation software ${ }^{B}$ in nonsequential raytracing mode. The light hitting the patient's cornea was modeled as a 3-dimension (3-D) Ganzfeld source (described previously ${ }^{21}$ ), which is a good model for normal (homogeneous) lighted surroundings. Between 1.7 million and 2.3 million rays were traced for each patient. The geometry of the eyes was built on patientspecific biometry data as specified in Table $2 .^{27}$

Because data on the optical design of the aspheric primary IOLs were not available, these were modeled as standard equi-biconvex spherical IOLs with a square edge that was at least $0.2 \mathrm{~mm}$ thick (Figure 1). For IOLs of low refractive index and/or large power, this leads to a clear optic diameter below the value of the primary IOL radial size. The geometry of the sulcus-fixated secondary IOL was based on a technical drawing that was provided by the manufacturer. The haptics were not considered for the primary and the secondary IOLs. In the optical model, the IOLs are free standing in aqueous humor with no mechanical support.

The optical model was a spherical equivalent (SE) model of the eye: corneal astigmatism was not considered and a single curvature was included in the model, taken as the average of flat keratometry and steep keratometry. When an aspheric toric sulcus-fixated IOL 
Table 2. Parameters used in the optical model.

\begin{tabular}{|c|c|c|}
\hline \multirow[b]{2}{*}{ Parameter } & \multicolumn{2}{|r|}{ Status } \\
\hline & Patient-Specific & Description \\
\hline \multicolumn{3}{|l|}{ Entered in the model } \\
\hline Cornea index & No & $1.3769^{27}$ \\
\hline Cornea anterior radius & Yes & Measured - average of $\mathrm{K} 1$ and $\mathrm{K} 2$ \\
\hline Cornea posterior radius & No & $0.853 \times$ (anterior radius) \\
\hline Cornea conicity & No & $\mathrm{K}=-0.26$ on both sides \\
\hline Anterior chamber index & No & $1.336^{27}$ \\
\hline Vitreous index & No & 1.336 \\
\hline Iris aperture & No & Varied from $1.5 \mathrm{~mm}$ to $5.0 \mathrm{~mm}$ \\
\hline Iris thickness (preop and postop) & Yes & Measured \\
\hline Iris position (preop and postop) & Yes & Measured \\
\hline Primary IOL position (preop and postop) & Yes & Measured \\
\hline Primary IOL central thickness & Yes & Measured \\
\hline Primary IOL index & Yes & Taken from manufacturer data \\
\hline Primary IOL radial size & Yes & Taken from manufacturer data \\
\hline Primary IOL optical surfaces curvature & No & Calculated based on IOL index and power \\
\hline Primary IOL edge design & No & Standard - see Figure 1 \\
\hline Primary IOL edge thickness & No & Assumed $\geq 0.2 \mathrm{~mm}$ \\
\hline Sulcus-fixated IOL position & Yes & Measured \\
\hline Sulcus-fixated IOL thickness & Yes & Measured \\
\hline Sulcus-fixated IOL radial size & No & Taken from manufacturer data \\
\hline Sulcus-fixated IOL curvatures & No & Taken from manufacturer data \\
\hline \multicolumn{3}{|l|}{ Calculated within the model } \\
\hline Primary IOL clear optic & Yes & Determined by edge thickness, IOL power, and IOL center thickness \\
\hline Cornea radial size & Yes & Determined by cornea curvature and iris position \\
\hline Retina radius & Yes & Determined by AL and cornea radial size \\
\hline
\end{tabular}

$\mathrm{AL}=$ axial length; $\mathrm{IOL}=$ intraocular lens; $\mathrm{K}=$ keratometry; $\mathrm{K} 1=$ flat keratometry; $\mathrm{K} 2$ = steep keratometry

was present, it was modeled as a spherical IOL of power equal to the SE of the toric IOL.

The retina was modeled by a spherical nonsequential detector of homogeneous sensitivity. The capsular bag was modeled with a shield, blocking any rays that missed the primary IOL. The 3-D Ganzfeld source was built as a spherical source of $1 \mathrm{~m}$ diameter emitting rays at each point of its surface following a Lambertian law. Chromaticity and ray splitting were not considered. For each eye, for 4 iris apertures, and for preoperative and postoperative cases, the full number of rays were traced and the light irradiance was calculated at each point of the detector. The data were then extracted in terms of irradiance per angle on retina (Figure 2). Because the eye model has a complete symmetry under

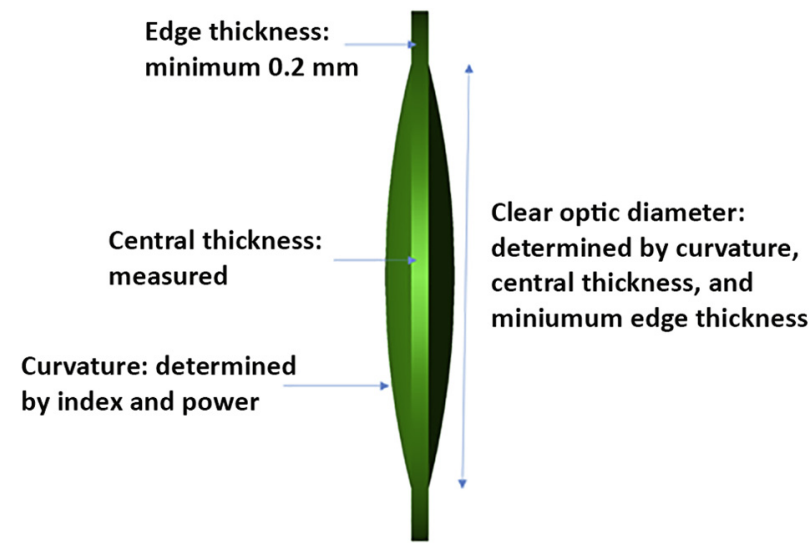

Figure 1. Geometry of a standard spherical equi-biconvex IOL with a standard edge. rotation around the optical axis, data were averaged in a cylindrical fashion allowing for a significant reduction of the noise that originates from the finite number of rays.

Following this, a conversion of the results from retinal space to visual space was carried out. At first, the relationship between the visual angle (eccentricity) and the angle on the retina was established by tracing rays from a collimated source placed at a variable eccentricity and by identifying the coordinate of the center of the light spot created on the retina. Thereafter, the irradiance results were converted to the visual space. The contribution of the rays hitting the retina before the capsular bag block was prevented.

\section{Analysis of Ray-Tracing Data}

The irradiance of light at the retina was evaluated as a function of degrees of eccentricity relative to the centrum of visual field and simulated with 4 iris apertures as follows: $1.5 \mathrm{~mm}, 2.5 \mathrm{~mm}$, $3.5 \mathrm{~mm}$, and $5.0 \mathrm{~mm}$. For better comparison and to compensate for a decrease in light irradiance with small pupils, the ratio was calculated between the mean irradiance in the peripheral retinal region (60 to 70 degrees of eccentricity) and the mean irradiance in a more central region of the retina (20 to 30 degrees of eccentricity), both for preoperative and postoperative data (Table S1, available at http://jcrsjournal.org). The postoperative ratio was divided by the preoperative ratio to assess for possible relative improvement in perceived light irradiances at eccentricities between 60 degrees and 70 degrees after sulcus-fixated IOL implantation.

\section{Statistical Analysis}

Data were collected using Excel software (Microsoft Office 2010, Microsoft Corp.) and analyzed using SPSS software (version 23.0, IBM Corp.). The means \pm SD were calculated for continuous variables. The statistical difference between the means of 


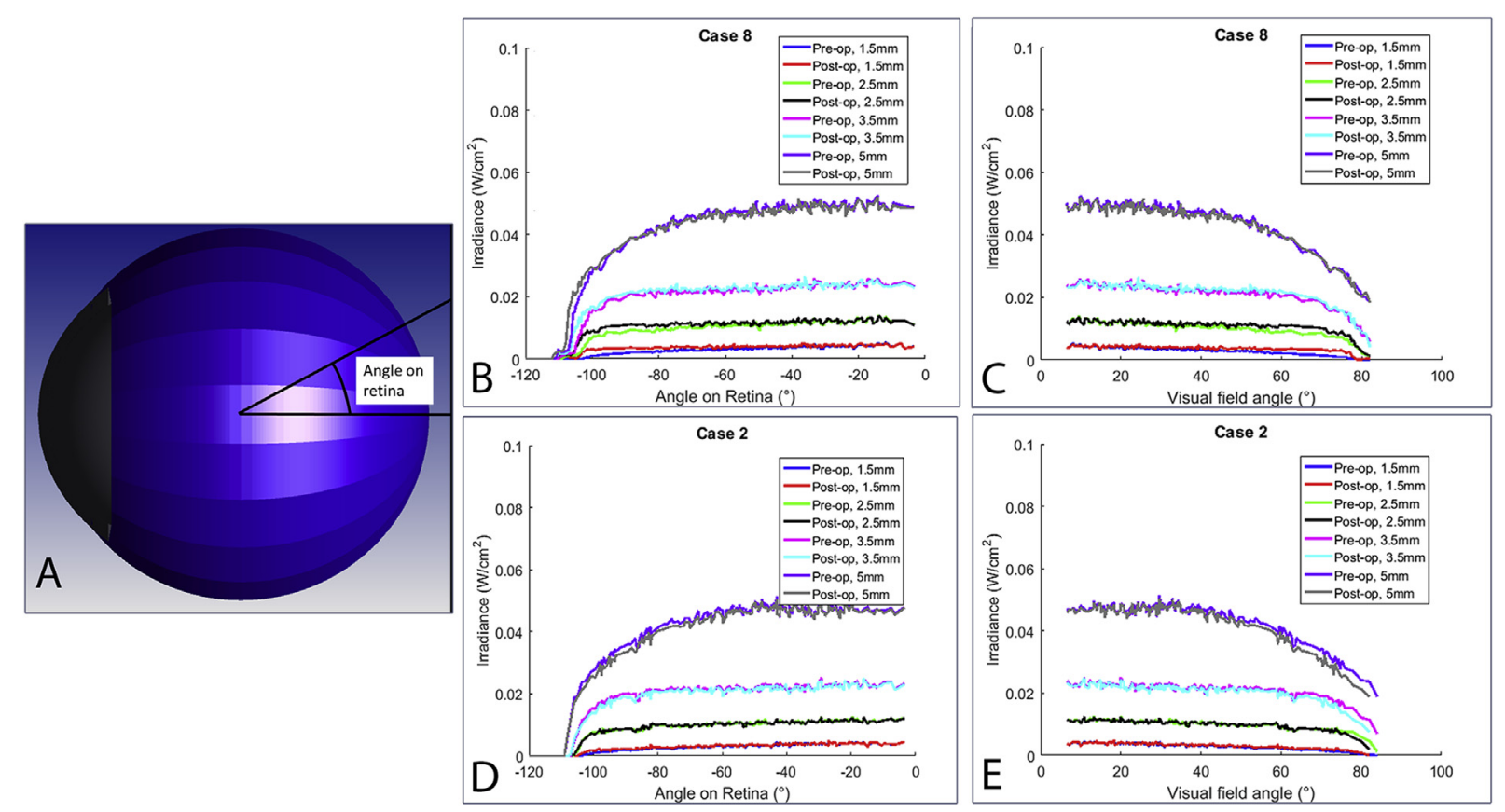

Figure 2. Example of the irradiance results obtained for the eye of patient 8 . A: Defined angle on retina. $B$ and $D$ : Results of the ray tracing for patient 8 (complete resolution of negative dysphotopsia) and patient 2 (no resolution of negative dysphotopsia), shown as the irradiance as a function of the angle on the retina for both the preoperative and postoperative case and for 4 different iris apertures. $C$ and $E$ : Irradiance as a function of the visual angle.

preoperative and postoperative parameters in patients with and without improvement of negative dysphotopsia was assessed with the independent-samples $t$ test. The paired-samples $t$ test was used to evaluate statistical differences between the simulated irradiance changes before and after sulcus-fixated IOL implantation. The statistical difference between the means of simulated relative irradiance changes at the periphery in patients with partial, complete, and no resolution of negative dysphotopsia was assessed with analysis of variance; $P$ values less than 0.05 were considered statistically significant.

\section{RESULTS}

\section{Clinical Data}

A sulcus-fixated IOL was implanted in 8 patients (10 eyes) with negative dysphotopsia (Tables $3 \mathrm{~A}$ and $3 \mathrm{~B}$ ). The mean age of the patients was $67.6 \pm 3.2$ years. These patients reported a bothersome black crescent, a black edge, or a blurred temporal spot. The symptoms developed after cataract surgery and increased in photopic conditions. After sulcus-fixated IOL implantation, negative dysphotopsia resolved completely in 6 eyes, partially in 2 eyes, and persisted in 2 eyes.

In 5 eyes, kinetic perimetry was performed before and after implantation of the sulcus-fixated IOL (Figure 3). Before surgery, 2 patients ( 3 eyes) reported the constriction of the inferior-temporal or temporal visual field by a black shadow and 2 patients ( 2 eyes) reported a blurred gray temporal spot. After sulcus-fixated IOL implantation, the extension of the visual field increased in patients reporting black shadows (Case 4 and 8 ) and both patients also reported subjective improvement of negative dysphotopsia. In Case 3, a relative scotoma was mapped during perimetry. After supplementary implantation of the sulcus-fixated
IOL, the relative scotoma increased in size concurrently with increased symptoms of negative dysphotopsia. In Case 5, a relative scotoma found before surgery completely resolved concurrently with resolution of the negative dysphotopsia after sulcus-fixated IOL implantation.

There were no statistically significant differences in age, anterior chamber dimensions, AL, IOL power, and photopic pupil diameters between patients with (partial) resolution and persistence of negative dysphotopsia (Table 4). There was a difference in the chord $\mu$ between patients assessed using the Holladay report of the Scheimpflug photography device. Two patients with no resolution of negative dysphotopsia had a larger chord $\mu$ of $0.66 \mathrm{~mm}$ (Case 2) and $0.31 \mathrm{~mm}$ (Case 3) after surgery than patients with complete or partial resolution of negative dysphotopsia (range 0.14 to $0.24 \mathrm{~mm}$ ). However, the preoperative data of chord $\mu$ were not available in all cases and therefore, it was not reported. In 2 patients (Case 5, left eye and Case 6 , left eye) the optic-haptic junction of the primary IOL and sulcus-fixated IOL was oriented superior-temporal at 1 o'clock and 7 o'clock and in 1 patient (Case 8), the optic-haptic junction of both the primary and sulcusfixated IOLs was oriented horizontally at 3 o'clock and 9 o'clock. The data of haptic junction of the IOLs' orientation were not available for other cases.

\section{Optical Modeling}

The irradiances of light between 60 degrees and 70 degrees of visual field were smaller than between 20 to 30 degrees of visual field (Figure 4 and Table S1, available at http: //jcrsjournal.org). Before sulcus-fixated IOL implantation, there was a marked decrease in the light irradiance at the 


\begin{tabular}{|c|c|c|c|c|c|c|c|}
\hline \multirow[b]{2}{*}{ Case } & \multicolumn{4}{|c|}{ Characteristic } & \multicolumn{2}{|c|}{ Cataract Surgery } & \multirow{2}{*}{$\begin{array}{c}\text { Negative Dysphotopsia } \\
\text { Patient Description of Symptoms }\end{array}$} \\
\hline & Eye & Age $(Y)$ & Sex & Comorbidity & IOL Type & IOL Power & \\
\hline $1^{*}$ & $\mathrm{R}$ & 69 & M & No & Acrysof SN60WF & 21 & Black crescent temporal \\
\hline $2^{*}$ & $\mathrm{R}$ & 70 & $\mathrm{~F}$ & Advanced AMD & Acrysof SN60WF & 23 & Black strip temporal \\
\hline 3 & $\mathrm{~L}$ & 64 & $\mathrm{~F}$ & No & Tecnis ZCB0O & 23 & $\begin{array}{c}\text { C-shaped gray spot between } 6 \text { and } 10 \text { clock hours, } \\
\text { more bothersome in photopic than in mesopic } \\
\text { conditions, obscured by frame of spectacles }\end{array}$ \\
\hline 4 & $\mathrm{R}$ & 64 & $\mathrm{~F}$ & No & Tecnis PCBOO & 27 & $\begin{array}{c}\text { Black edges inferior-temporal in both eyes, similar to } \\
\text { looking through ski goggles that constrict visual } \\
\text { field, worse in bright light conditions, obscured by } \\
\text { frame of spectacles }\end{array}$ \\
\hline 4 & L & 64 & $\mathrm{~F}$ & No & Tecnis PCBOO & 26.5 & $\begin{array}{c}\text { Black edges inferior-temporal in both eyes, similar to } \\
\text { looking through ski goggles that constrict visual } \\
\text { field, worse in bright light conditions, obscured by } \\
\text { frame of spectacles }\end{array}$ \\
\hline 5 & L & 67 & M & Amblyopia & Acrysof SN60WF & 25.5 & $\begin{array}{c}\text { Blurred colorless spot from } 7 \text { to } 8 \text { clock hours } \\
\text { temporal, more bothersome in photopic than in } \\
\text { mesopic conditions }\end{array}$ \\
\hline $6^{*}$ & $\mathrm{~L}$ & 69 & $\mathrm{~F}$ & No & Tecnis ZCBOO & 21 & Black edge at the temporal periphery \\
\hline $6^{\star}$ & $\mathrm{R}$ & 70 & $\mathrm{~F}$ & No & Tecnis ZCB00 & 22 & $\begin{array}{c}\text { Black edge at the temporal periphery and light } \\
\text { flickering }\end{array}$ \\
\hline 7 & $\mathrm{~L}$ & 65 & $\mathrm{~F}$ & No & Acrysof SN60WF & 26.5 & $\begin{array}{c}\text { Gray edge temporal, worse in photopic conditions, } \\
\text { obscured by frame of spectacles }\end{array}$ \\
\hline 8 & $\mathrm{~L}$ & 73 & $\mathrm{~F}$ & Early AMD & Acrysof SN60WF & 21 & Oscillating black curtain temporal \\
\hline
\end{tabular}

$\mathrm{AMD}=$ age-related macular degeneration; $\mathrm{IOL}=$ intraocular lens

${ }^{\star}$ This patient's data were reported previously ${ }^{25}$

periphery with a $1.5 \mathrm{~mm}$ pupil diameter that was less obvious with larger pupil diameters (Figure 4, A). After sulcus-fixated IOL implantation, ray-tracing simulation showed a significant increase in light irradiance at the periphery with $1.5 \mathrm{~mm}$ pupil diameter (mean difference in irradiance ratios of $0.22, P<.05$ ) (Figures $4, \mathrm{~B}$, and 5). This increase was greater for patients in which the negative dysphotopsia resolved completely than those with partial resolution of negative dysphotopsia or persistent negative dysphotopsia (Figure 6), although not significant $(P=.065)$. There was no improvement in patients with larger pupils. In addition, there was no consistent relationship between light irradiance at the periphery and anterior or posterior chamber dimensions, AL, or IOL power (data not shown).

\section{DISCUSSION}

The development of negative dysphotopsia after cataract surgery as well as the chance of its resolution, either spontaneously or after a variety of treatments, cannot yet be predicted. In addition, even after extensive research, the pathophysiologic mechanisms underlying negative dysphotopsia are still unclear. Various IOL-related and eye-related factors have been suggested to play a role in the pathogenesis of negative dysphotopsia ${ }^{1-3,7-17,20-22,28}$ and therefore, negative dysphotopsia is considered at present to be a multifactorial phenomenon caused by an interaction between IOL optics and a predisposed eye. ${ }^{1-3,18,19}$ This conception is also supported by the current study in which optical modeling that combines all biometry results of a given patient seems to provide some insight into the course of negative dysphotopsia.

In this study, we did not find a relationship between the course of negative dysphotopsia after implantation of a sulcus-fixated IOL and the characteristics of the IOLs or patients such as age, IOL power, $\mathrm{AL}$, anterior and posterior chamber dimensions, or photopic pupil diameter. In our previous study, ${ }^{11}$ we reported that negative dysphotopsia patients, had significantly shorter eyes than asymptomatic controls $(22.7 \pm 0.7 \mathrm{~mm}$ versus $24.4 \pm 0.93 \mathrm{~mm})$ and were implanted with IOLs of higher power $(23.8 \pm 2.2 \mathrm{D}$ versus $19.5 \pm 2.5 \mathrm{D}$ ). Although the eyes with negative dysphotopsia analyzed in the current study had a similar mean AL of $22.7 \pm 0.7 \mathrm{~mm}$ and a mean IOL power of $23.7 \pm 2.5 \mathrm{D}$, these parameters were not statistically different in patients with and without resolution of negative dysphotopsia after surgery. However, an equi-convex design in combination with a higher dioptric power as well as square edges and acrylic material of the IOL might have predisposed our patients to the development of negative dysphotopsia.?

Although negative dysphotopsia symptoms were worse in photopic conditions, we did not find a statistically significant relationship between the course of negative dysphotopsia and photopic pupil diameters before or after sulcus-fixated IOL implantation. Although worsening of negative dysphotopsia in photopic conditions is acknowledged by previous research, ${ }^{2,3,5}$ negative dysphotopsia might either improve ${ }^{2}$ or persist in mydriasis (Case 3 of this study). To our knowledge, no systematic intraindividual evaluation of negative dysphotopsia symptoms with 


\begin{tabular}{|c|c|c|c|c|c|c|c|}
\hline Case & Eye & Date & IOL Type (Power) & 1 W Postop & 1 Mo Postop & Resolution & Complications \\
\hline $1^{*}$ & $\mathrm{R}$ & Apr 2014 & 653L (0.0 D) & $\begin{array}{l}\text { Crescent decreased and } \\
\text { was not bothersome }\end{array}$ & Complete resolution & Complete & No \\
\hline $2^{*}$ & $\mathrm{R}$ & Jun 2014 & 653L (0.0 D) & $\begin{array}{l}\text { Strip decreased and } \\
\text { visual acuity } \\
\text { subjectively improved }\end{array}$ & $\begin{array}{l}\text { Strip is recovered in } \\
\text { size and was still } \\
\text { bothersome }\end{array}$ & No & No \\
\hline 3 & L & Jun 2015 & $653 \mathrm{~L} \quad(0.0 \mathrm{D})$ & $\begin{array}{l}\text { Spot moved to superior } \\
\text { temporal direction }\end{array}$ & $\begin{array}{l}\text { Size of spot increased; } \\
\text { spot was especially } \\
\text { bothersome in } \\
\text { mydriasis and in } \\
\text { bright artificial light } \\
\text { conditions }\end{array}$ & No & No \\
\hline 4 & $\mathrm{R}$ & Jun 2016 & 653L (0.0 D) & Black edge decreased & $\begin{array}{l}\text { Black edges became } \\
\text { very small and } \\
\text { transparent, and } \\
\text { visual field was no } \\
\text { longer subjectively } \\
\text { constricted }\end{array}$ & Partial & No \\
\hline 4 & L & May 2016 & $653 \mathrm{~L} \quad(0.0 \mathrm{D})$ & Black edge decreased & $\begin{array}{l}\text { Black edges became } \\
\text { very small and } \\
\text { transparent, and } \\
\text { visual field was no } \\
\text { longer subjectively } \\
\text { constricted }\end{array}$ & Partial & No \\
\hline 5 & L & Mar 2015 & 653L (0.5 D) & Blurred spot is gone & Complete resolution & Complete & No \\
\hline $6^{*}$ & L & Jul 2014 & $653 \mathrm{~L} \quad(0.0 \mathrm{D})$ & Black edge is gone & $\begin{array}{l}\text { Complete resolution, } \\
\text { but patient reported } \\
\text { light strip and light } \\
\text { flickering }\end{array}$ & Complete & Light flickering \\
\hline $6^{*}$ & $\mathrm{R}$ & Mar 2014 & 653L (0.0 D) & $\begin{array}{l}\text { Black edge and flickering } \\
\text { are gone }\end{array}$ & $\begin{array}{l}\text { Complete resolution of } \\
\text { flickering and black } \\
\text { edges }\end{array}$ & Complete & No \\
\hline 7 & $\mathrm{~L}$ & Jun 2015 & $653 \mathrm{~T}(0.0-1.5 \times 94)$ & Gray edge is gone & $\begin{array}{l}\text { Complete resolution of } \\
\text { gray edge, but } \\
\text { patient reported } \\
\text { general light } \\
\text { sensitivity }\end{array}$ & Complete & Glare \\
\hline 8 & L & Jun 2016 & 653L (0.0 D) & Black curtain is gone & Complete resolution & Complete & No \\
\hline
\end{tabular}

$\mathrm{IOL}=$ intraocular lens

${ }^{\star}$ This patient's data were reported previously ${ }^{25}$

different pupil diameters and in different light conditions has yet been reported.

According to a recent study, ${ }^{7}$ angle $\kappa$ can be considered as 1 of the primary causative factors and a chord length $\kappa$ (approximation of angle $\kappa$ ) longer than $0.44 \mathrm{~mm}$ can be associated with a higher risk for negative dysphotopsia. All but 1 of our patients had a chord length $\kappa$ shorter than $0.44 \mathrm{~mm}$. Of note, the 2 patients with a longer chord length $\kappa$ had no resolution of negative dysphotopsia after surgery. Chord length $\kappa$ was the only biometric factor that was associated with the course of negative dysphotopsia in this study.

It has been proposed that a distance between an IOL and a posterior iris surface larger than $0.5 \mathrm{~mm}$ might predispose some patients to negative dysphotopsia and that reduction of this distance might lead to resolution of symptoms. ${ }^{3,16}$ In contrast, the last optical simulation analysis by Holladay and Simpson ${ }^{7}$ suggested a smaller axial distance of the IOL behind the iris as the primary causative factor. In this study, the iris-IOL distance measured with AS-OCT before surgery was less than $0.5 \mathrm{~mm}$ in 2 eyes and larger than $0.5 \mathrm{~mm}$ in 8 eyes, and after surgery the sulcus-fixated IOL was adjacent to the posterior iris surface in all cases. We did not find a significant relationship between the iris-IOL distance and the course of negative dysphotopsia after sulcus-fixated IOL implantation. Moreover, in 2 eyes, negative dysphotopsia persisted despite a shallow posterior chamber after sulcus-fixated IOL implantation.

Recently, an inferior-temporal location of the optic-haptic junction of the IOL was shown to be associated with a 2.3-fold decrease in the risk for transient negative dysphotopsia at 1 day after surgery compared with a vertical location of the optic-haptic junction. ${ }^{12}$ However, this association was absent at 1 week and 1 month after surgery and thus was not considered to be related to persistent negative dysphotopsia. ${ }^{12}$ In our study, the optic-haptic junction was 


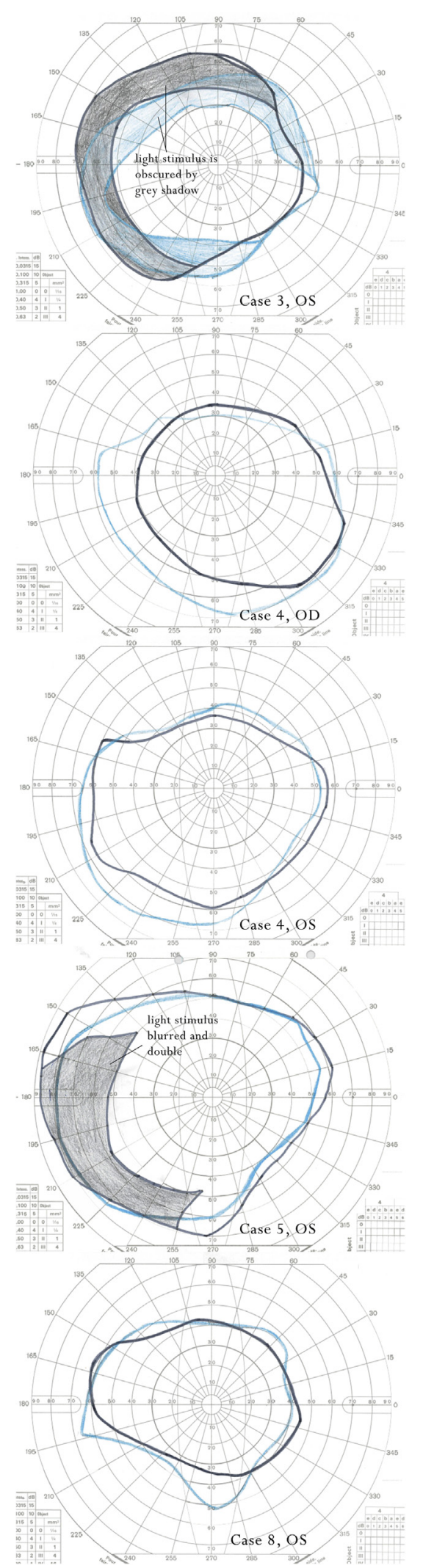

Figure 3. The V4e isopters of patients with negative dysphotopsia before (gray line) and after (blue line) sulcus-fixated IOL implantation. (The preoperative visual fields of these cases were reported previously. ${ }^{11}$ ) oriented superior-temporally in 2 cases and horizontally in 1 case with persistent negative dysphotopsia, which was completely resolved after implantation of the sulcusfixated IOL. Because the optic-haptic junction of the sulcus-fixated IOL was positioned above that of the primary IOL in these cases, it is unlikely that the position of the optic-haptic junction of sulcus-fixated IOL could lead to the resolution of negative dysphotopsia.

In a previous study, ${ }^{11}$ we found that patients with negative dysphotopsia compared with asymptomatic pseudophakic patients had either constriction of their inferior temporal visual field or a relative scotoma between 50 degrees and 90 degrees of the temporal visual fields mapped by kinetic perimetry. Five eyes from the previous study were treated with implantation of the sulcus-fixated IOL. Visual field changes, such as an increase in the constricted visual field and a resolution or increase in the relative scotoma after sulcus-fixated IOL implantation, matched the course of negative dysphotopsia after surgery. This confirms our statement that kinetic perimetry can support the diagnosis of negative dysphotopsia and should be used for the objective evaluation of the course of negative dysphotopsia.

To account for the multifactorial nature of negative dysphotopsia, we combined IOL-related parameters with clinical data in patient-specific eye models before and after sulcus-fixated IOL implantation. In our analysis, we focused on the simulated light irradiance between 60 degrees and 70 degrees of visual field because changes were noticed in this region before and after surgery. Our approach showed that all simulated cases had a marked decrease in light irradiance at the periphery before sulcus-fixated IOL implantation that was especially prominent with the smallest pupil diameter of $1.5 \mathrm{~mm}$. Implantation of the sulcus-fixated IOL led to a significant increase $(P<.05)$ in the simulated light irradiance at the periphery with the $1.5 \mathrm{~mm}$ pupil diameter, which was smaller although not significant $(P=.065)$ in cases in which negative dysphotopsia persisted after surgery compared with cases in which an improvement or a complete resolution of the symptoms occurred. Holladay and Simpson ${ }^{7}$ suggested that implantation of a piggyback IOL can shift the rays refracted by the IOL and thereby move the shadow toward a more peripheral part of the visual field. The shift of light irradiance caused by introduction of the plano surfaces of the sulcus-fixated IOL in the optical system in combination with the effect of the larger optic diameter $(6.5 \mathrm{~mm})$ of this $\mathrm{IOL}^{7}$ might lead to the postoperative increase in light irradiance in our study.

A recent ray-tracing analysis of Holladay and Simpson, based on general pseudophakic eye models, showed a 2.6-degree shadow between 85.7 degrees and 88.3 degrees of retinal field angle, which was formed between the rays refracted by the IOL and the rays missing the IOL, that would potentially result in a shadow near 90 degrees of the visual field. Our patient-specific ray-tracing modeling showed a decrease in irradiance despite the blockage of rays missing 
Table 4. Preoperative and postoperative characteristics of patients with and without improvement in negative dysphotopsia after sulcus-fixated IOL implantation.

\begin{tabular}{|c|c|c|c|}
\hline \multirow[b]{2}{*}{ Parameter } & \multicolumn{2}{|c|}{ Mean \pm SD } & \multirow[b]{2}{*}{$P$ Value } \\
\hline & Improvement $(n=8)$ & No Improvement $(n=2)$ & \\
\hline \multicolumn{4}{|l|}{ Before sulcus-fixated IOL implantation } \\
\hline Age $(y)$ & $68 \pm 3$ & $67 \pm 4$ & .78 \\
\hline IOL power (D) & $24 \pm 3$ & $23 \pm 0$ & .44 \\
\hline $\mathrm{AL}(\mathrm{mm})$ & $22.6 \pm 0.5$ & $23.2 \pm 1.3$ & .27 \\
\hline $\mathrm{ACW}(\mathrm{mm})$ & $11.6 \pm 0.2$ & $11.4 \pm 0.7$ & .81 \\
\hline $\mathrm{ACD}(\mathrm{mm})$ & $4.26 \pm 0.7$ & $4.24 \pm 0.71$ & .98 \\
\hline $\mathrm{ACV}\left(\mathrm{mm}^{3}\right)$ & $173 \pm 33$ & $174 \pm 68$ & .97 \\
\hline Lens vault (mm) & $-0.98 \pm 0.19$ & $-1.22 \pm 0.06$ & .12 \\
\hline Photopic pupil diameter (mm) & $2.65 \pm 0.57$ & $2.86 \pm 0.78$ & .67 \\
\hline Iris-IOL distance $(\mathrm{mm})$ & $0.57 \pm 0.13$ & $0.68 \pm 0.18$ & .33 \\
\hline \multicolumn{4}{|l|}{ Angle opening distance at $500 \mu \mathrm{m}(\mathrm{mm})$} \\
\hline Temporal & $0.59 \pm 0.22$ & $0.48 \pm 0.12$ & .54 \\
\hline Nasal & $0.54 \pm 0.23$ & $0.6 \pm 0.4$ & .73 \\
\hline \multicolumn{4}{|l|}{ Angle opening distance at $750 \mu \mathrm{m}(\mathrm{mm})$} \\
\hline Temporal & $0.81 \pm 0.3$ & $0.64 \pm 0.16$ & .48 \\
\hline Nasal & $0.77 \pm 0.33$ & $0.84 \pm 0.17$ & .76 \\
\hline \multicolumn{4}{|l|}{ Trabecular iris space area at $500 \mu \mathrm{m}(\mathrm{mm})$} \\
\hline Temporal & $0.2 \pm 0.08$ & $0.16 \pm 0.09$ & .61 \\
\hline Nasal & $0.2 \pm 0.09$ & $0.23 \pm 0.07$ & .67 \\
\hline \multicolumn{4}{|l|}{ Trabecular iris space area at $750 \mu \mathrm{m}(\mathrm{mm})$} \\
\hline Temporal & $0.38 \pm 0.15$ & $0.31 \pm 0.12$ & .55 \\
\hline Nasal & $0.37 \pm 0.15$ & $0.43 \pm 0.12$ & .61 \\
\hline \multicolumn{4}{|l|}{1 mo after sulcus-fixated IOL implantation } \\
\hline $\mathrm{ACD}(\mathrm{mm})$ & $3.2 \pm 0.29$ & $3.17 \pm 0.56$ & .92 \\
\hline $\mathrm{ACV}\left(\mathrm{mm}^{3}\right)$ & $154 \pm 24$ & $150 \pm 62$ & .88 \\
\hline Photopic pupil diameter (mm) & $2.73 \pm 0.41$ & $3.04 \pm 1.11$ & .76 \\
\hline Distance between primary and sulcus-fixated IOLs (mm) & $0.54 \pm 0.12$ & $0.59 \pm 0.22$ & .64 \\
\hline \multicolumn{4}{|l|}{ Angle opening distance at $500 \mu \mathrm{m}(\mathrm{mm})$} \\
\hline Temporal & $0.49 \pm 0.15$ & $0.46 \pm 0.21$ & .82 \\
\hline Nasal & $0.46 \pm 0.19$ & $0.46 \pm 0.32$ & .98 \\
\hline \multicolumn{4}{|l|}{ Angle opening distance at $750 \mu \mathrm{m}(\mathrm{mm})$} \\
\hline Temporal & $0.7 \pm 0.22$ & $0.63 \pm 0.25$ & .71 \\
\hline Nasal & $0.64 \pm 0.31$ & $0.7 \pm 0.49$ & .82 \\
\hline \multicolumn{4}{|l|}{ Trabecular iris space area at $500 \mu \mathrm{m}(\mathrm{mm})$} \\
\hline Temporal & $0.17 \pm 0.06$ & $0.15 \pm 0.09$ & .68 \\
\hline Nasal & $0.17 \pm 0.07$ & $0.15 \pm 0.12$ & .76 \\
\hline \multicolumn{4}{|l|}{ Trabecular iris space area at $750 \mu \mathrm{m}(\mathrm{mm})$} \\
\hline Temporal & $0.31 \pm 0.13$ & $0.29 \pm 0.21$ & .84 \\
\hline Nasal & $0.32 \pm 0.1$ & $0.29 \pm 0.14$ & .72 \\
\hline
\end{tabular}

$\mathrm{AL}=$ axial length; $\mathrm{ACD}=$ anterior chamber depth; $\mathrm{ACV}=$ anterior chamber volume; $\mathrm{ACW}=$ anterior chamber width; $\mathrm{IOL}=$ intraocular lens

the IOL. Moreover, this decrease occurred more centrally than the shadow described by Holladay and Simpson, and is in accordance with our clinical perimetric data.

In the present study, we did not find a clear correlation between simulated decreased light irradiance at the periphery and biometric data of the simulated cases. This might be related to the small number of cases with persistence of negative dysphotopsia after surgery and the limitations of our modeling. Only 10 eyes were simulated in this study, and in 5 eyes, the results were

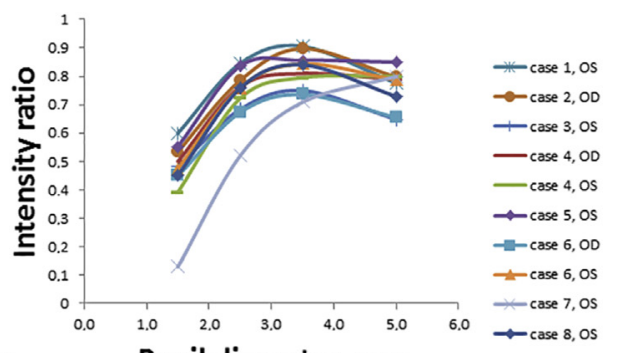

A
B

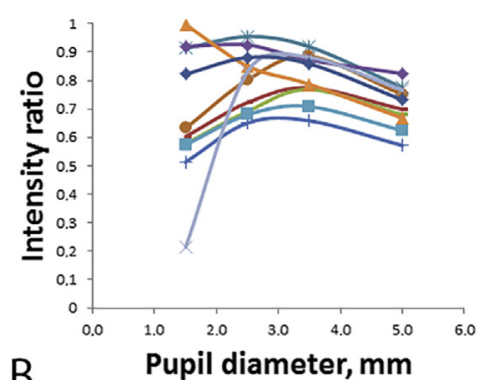

*- case 1 , os $\rightarrow$ cose 2,00 —-case 3 , os - case 4,00 —case 4,05 $\rightarrow$ case 5, os $\rightarrow$ - case 6,00 \pm case 6,05 $\div$ case 7, os Pupil diameter, $\mathrm{mm}$
Figure 4. Preoperative $(A)$ and postoperative $(B)$ light irradiance decrease in the peripheral retinal region (60 to 70 degrees of eccentricity) relative to the mean irradiance in a more central region of the retina (20 to 30 degrees of eccentricity) simulated with $1.5 \mathrm{~mm}$, $2.5 \mathrm{~mm}, 3.5 \mathrm{~mm}$, and $5.0 \mathrm{~mm}$ iris aperture. 


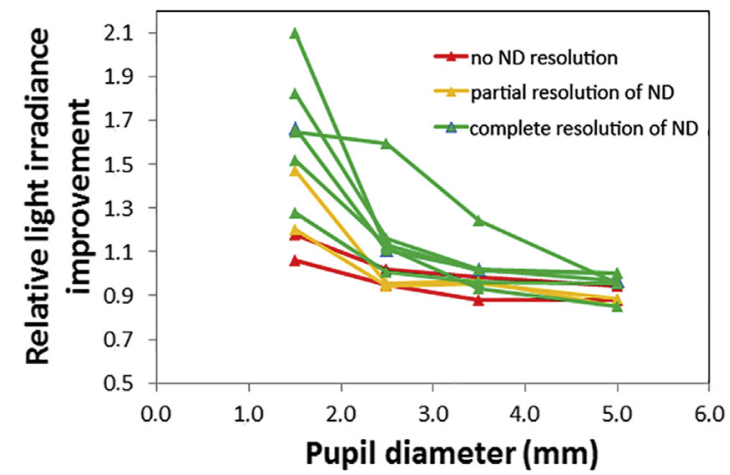

Figure 5. Relative irradiance improvement in the peripheral retinal region calculated by dividing the postoperative irradiance ratio by the preoperative irradiance ratio (ND $=$ negative dysphotopsia).

supported by Goldmann kinetic perimetry for which variable visual field changes (increase of the extension of inferior temporal visual field, resolution, or increase of the relative scotoma) were noted. Peripheral visual field evaluation should be included in routine examinations of patients with negative dysphotopsia to establish a specific region of interest in which shadows can be detected. ${ }^{29} \mathrm{~A}$ more extensive combination of clinical and laboratory research is required to predict and understand the effect of sulcus-fixated IOLs as well as the other negative dysphotopsia treatment modalities on a patient-by-patient basis.

All patients were implanted with square-edged IOLs: Acrysof SN60WF (Alcon Laboratories, Inc.), Tecnis ZCB00, or Tecnis PCB00 (both Abbott Medical Optics, Inc.) (Table 3A). However, a simplified model of the primary IOL (spherical IOL with a standard sharp edge) was used in all cases. Because the data about transparency of the anterior and peripheral lens capsule were not documented in all cases, we did not simulate the effect of the capsulorhexis. Therefore, our results cannot be compared with the modeling of Hong et al., ${ }^{23}$ where the interaction between

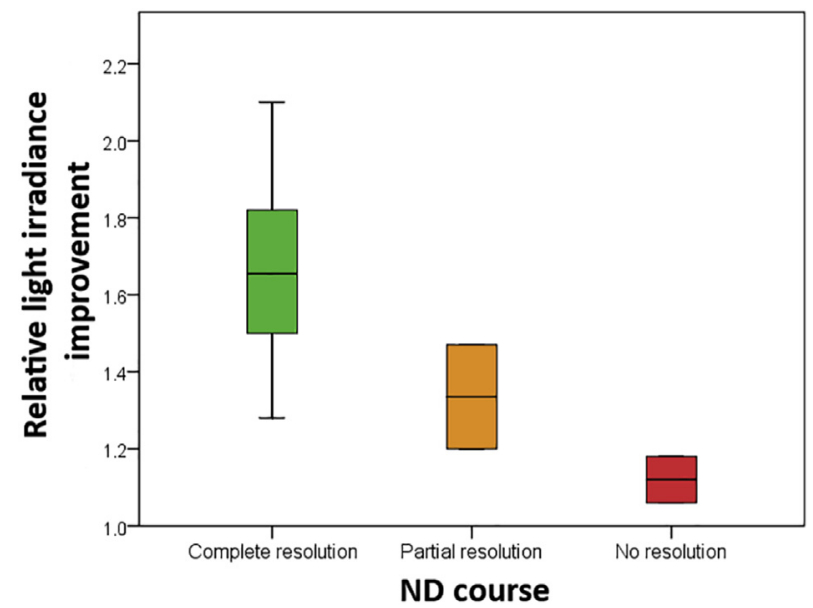

Figure 6. Relative light irradiance improvement in the peripheral retinal region after surgery simulated with $1.5 \mathrm{~mm}$ iris aperture in eyes with complete $(n=6)$, partial $(n=2)$, and no resolution $(\mathrm{n}=2)$ of negative dysphotopsia (ND = negative dysphotopsia). anterior capsulorhexis and IOL was proposed to cause negative dysphotopsia by creating shadows on the retina. Although various treatment strategies directed to the IOLcapsule bag interface have been suggested, there are very limited data on the success rates. Reverse optic capture resulted in complete resolution of negative dysphotopsia in 3 cases, ${ }^{2}$ nasal IOL optic truncation in complete resolution in 1 case, ${ }^{30}$ and Nd:YAG anterior capsulotomy in complete resolution of negative dysphotopsia in 4 cases, in partial resolution in 2 cases, and no resolution in 1 case. ${ }^{8,9}$ The potential role of the IOL-capsule bag interface was further highlighted by a successful preventive role of primary reverse optic capture in patients with negative dysphotopsia in the first eye who were scheduled for cataract surgery in the fellow eye. ${ }^{2,31}$ An additional modeling with patient-specific data (including visual field evaluation and assessment of capsular bag transparency anterior and peripheral to the IOL optic) might help to further evaluate the role of capsulorhexis as well as the rays missing the IOL in the pathogenesis of negative dysphotopsia. However, a clinical technique should be developed first for the assessment of capsular bag transparency in vivo.

Simulation of the piggyback IOL by Hong et al. ${ }^{23}$ showed multiple surface reflections that filled the shadow created by the IOL-capsulorhexis interface. In the current study, ray splitting was not considered. This assumption is not thought to affect the results of the modeling as most of the light energy is carried by the main ray and our analysis relies on irradiance distribution, that is, energy per unit of time and area (the energy reflection coefficient is $0.3 \%$ for an IOL of index 1.5 placed in the eye). Thus, the sole multiple reflections included in the model were multiple total internal reflections. These reflections occur inside the sulcus-fixated IOL and were observed only for extreme angles and pupil diameters; these rays were found to consistently fall outside the range of the visual field and were therefore disregarded as a contributor to the appearance or resolution of negative dysphotopsia.

In conclusion, from all individual biometry results, only angle $\kappa$ showed a relationship with the course of negative dysphotopsia after sulcus-fixated IOL implantation. Raytracing modeling that combines individual biometry data showed an increase in the light irradiance at the periphery after sulcus-fixated IOL implantations that was also associated with the course of negative dysphotopsia. More cases as well as improvements in the model are required to understand anatomical or IOL-related factors that might explain this association. Possible improvements to the model include (1) a more realistic model of the capsular bag combined with developing a clinical diagnostic method; (2) a more accurate model of the IOL with regard to the optic, edge, and haptic design, including the effects of ray splitting; (3) building a non-rotationally symmetric eye model that considers patient-specific angle $\kappa$; and (4) simulation of the effect of higher-order aberrations. Most importantly, the model can be used to assess in greater detail the reasons for the change in irradiance patterns before implantation and after implantation of a 
secondary IOL, and gain a better understanding of the reasons for the difference between patients. This might open the path to predict the effect of implantation of a sulcus-fixated IOL in treating negative dysphotopsia symptoms on a patient-by-patient basis.

\section{WHAT WAS KNOWN}

- Negative dysphotopsia is a common side effect of cataract surgery that is probably caused by blockage of light at the peripheral nasal retina as a result of the interaction between the optics of the IOL and the anatomically predisposed eye.

- Sulcus-fixated IOL implantation in the ciliary sulcus can effectively treat severe negative dysphotopsia in about $80 \%$ of cases, although the mechanism of its effect is currently unknown.

\section{WHAT THIS PAPER ADDS}

- The course of negative dysphotopsia after sulcus-fixated IOL implantation was not related to the patient's age or individual biometry results such as $\mathrm{AL}, \mathrm{IOL}$ power, photopic pupil diameter, or dimensions of anterior and posterior eye chambers.

- Ray-tracing models showed a decrease in light irradiance at the periphery relative to the center of visual field in eyes, which increased significantly after sulcus-fixated IOL implantation.

- Combining individual biometric parameters and ray-tracing optical modeling showed a promising association with the course of negative dysphotopsia after sulcus-fixated IOL implantation and might be helpful in explaining the multifactorial nature of negative dysphotopsia.

\section{REFERENCES}

1. Davison JA. Positive and negative dysphotopsia in patients with acrylic intraocular lenses. J Cataract Refract Surg 2000; 26:1346-1355

2. Masket S, Fram NR. Pseudophakic negative dysphotopsia: surgical management and new theory of etiology. J Cataract Refract Surg 2011; 37:1199-1207

3. Osher RH. Negative dysphotopsia: long-term study and possible explanation for transient symptoms. J Cataract Refract Surg 2008; 34:1699-1707

4. Stulting RD. Cataract surgical problem. In: Masket S, ed, Consultation sec tion. J Cataract Refract Surg 2005; 31:651-652

5. Trattler WB, Whitsett JC, Simone PA. Negative dysphotopsia after intraocular lens implantation irrespective of design and material. J Cataract Refract Surg 2005; 31:841-845

6. Henderson BA, Geneva II. Negative dysphotopsia: a perfect storm. J Cataract Refract Surg 2015; 41:2291-2312

7. Holladay JT, Simpson MJ. Negative dysphotopsia: causes and rationale for prevention and treatment. J Cataract Refract Surg 2017; 43:263-275

8. Cooke DL, Kasko S, Platt LO. Resolution of negative dysphotopsia after laser anterior capsulotomy. J Cataract Refract Surg 2013; 39:1107-1109

9. Folden DV. Neodymium:YAG laser anterior capsulectomy: surgical option in the management of negative dysphotopsia. J Cataract Refract Surg 2013; 39:1110-1115

10. Davison JA. Clinical performance of Alcon SA30AL and SA60AT single-piece acrylic intraocular lenses. J Cataract Refract Surg 2002; 28:1112-1123

11. Makhotkina NY, Berendschot TTJM, Nuijts RMMA. Objective evaluation of negative dysphotopsia with Goldmann kinetic perimetry. J Cataract Refract Surg 2016; 42:1626-1633

12. Henderson BA, Yi DH, Constantine JB, Geneva II. New preventative approach for negative dysphotopsia. J Cataract Refract Surg 2016; 42:1449-1455

13. Narváez J, Banning CS, Stulting RD. Negative dysphotopsia associated with implantation of the Z9000 intraocular lens. J Cataract Refract Surg 2005; 31:846-847

14. Olson RJ. Cataract surgical problem. In: Masket S, ed, Consultation section. J Cataract Refract Surg 2005; 31:653-654

15. Fishkind WJ. Cataract surgical problem. In: Masket S, ed, Consultation section. J Cataract Refract Surg 2006; 32:908-909
16. Vámosi P, Csákány B, Németh J. Intraocular lens exchange in patients with negative dysphotopsia symptoms. J Cataract Refract Surg 2010; 36:418424

17. Masket S, Fram N. Etiology of negative dysphotopsia [letter]. J Cataract Refract Surg 2013; 39:485-486

18. Radford SW, Carlsson AM, Barrett GD. Comparison of pseudophakic dysphotopsia with Akreos Adapt and SN60-AT intraocular lenses. J Cataract Refract Surg 2007; 33:88-93

19. Simpson MJ. Double image in far peripheral vision of pseudophakic eye as source of negative dysphotopsia. J Opt Soc Am A Opt Image Sci Vis 2014; 31:2642-2649

20. Holladay JT. Reply to letter by S Masket and N Fram. Etiology of negative dysphotopsia. J Cataract Refract Surg 2013; 39:486.e1-486.e4

21. Holladay JT, Zhao H, Reisin CR. Negative dysphotopsia: the enigmatic penumbra. J Cataract Refract Surg 2012; 38:1251-1265. Available at: http: //www.hicsoap.com/publications/107\%20Neg\%20Dys\%20FINAL\%2OPUB \%20JCRS\%20July\%202012_38_1251-1265.pdf. Accessed December 16, 2017

22. Arnold PN. Cataract surgical problem. In: Masket S, ed, Consultation sec tion. J Cataract Refract Surg 2005; 31:1487-1488

23. Hong $X$, Liu $Y$, Karakelle M, Masket S, Fram NR. Ray-tracing optical modeling of negative dysphotopsia. J Biomed Opt 2011; 16 (12):125001

24. Burke TR, Benjamin L. Sulcus-fixated intraocular lens implantation for the management of negative dysphotopsia. J Cataract Refract Surg 2014; 40:1469-1472

25. Makhotkina NY, Berendschot TTJM, Beckers HJM, Nuijts RMMA. Treatment of negative dysphotopsia with supplementary implantation of a sulcus-fixated intraocular lens. Graefes Arch Clin Exp Ophthalmol 2015: 253:973-977

26. Weinstein A. Surgical experience with pseudophakic negative dysphotopsia [letter]. J Cataract Refract Surg 2012; 38:561; reply by S Masket, 561

27. Gross H, Blechinger F, Achtner B. Human Eye. In: Gross H, Blechinger F, Achtner B, eds, Handbook of Optical Systems, volume 4: Survey of Optical Instruments. Weinheim, Germany, Wiley-VCH Verlag GmbH \& Co. KGaA 2008; chapter 36

28. Franchini A. Cataract surgical problem. In: Masket S, ed, Consultation section. J Cataract Refract Surg 2005; 31:656

29. Simpson MJ. Mini-review: far peripheral vision. Vision Res 2017; 140:96105

30. Alapati NM, Harocopos GJ, Sheybani A. In-the-bag nasal intraocular lens optic truncation for treatment of negative dysphotopsia. J Cataract Refract Surg 2016; 42:1702-1706. Available at: http://www.jcrsjournal.org/article/S0886 -3350(16)30454-0/pdf. Accessed December 16, 2017

31. Narang P, Narang S. Primary reverse optic capture with implantation of capsular tension ring to prevent pseudophakic negative dysphotopsia J Cataract Refract Surg 2015; 41:891-892

\section{OTHER CITED MATERIAL}

A. Holladay JT. Pentacam Interpretation Guideline (Software $1.20 \mathrm{~b} 76$ or later). Holladay Report 2016. Available at: http://www.hicsoap.com/docs/Holla day\%20Report\%202016\%20-\%20Pentacam\%20Interpretation\%20Guidel nes.pdf. Accessed December 16, 2017

B. Zemax® Optical Design Program User's Manual, July 8, 2011. Redmond WA, Radiant Zemax LLC, 1990-2011. Available at: https://neurophysics .ucsd.edu/Manuals/Zemax/ZemaxManual.pdf. Accessed December 16, 2017

Disclosures: Drs. Dugrain and Purchase are employees of Rayner Intraocular Lenses, Ltd. Dr. Nuijts is a consultant to Alcon Laboratories, Inc. ASICO LLC, and Théa Pharma GmbH. He received study grants from Abbott Medical Optics, Inc., Alcon Laboratories, Inc., Gebauer Co., Humanoptics AG, Oculentis $\mathrm{GmbH}$, and Ophtec BV. He received lecture fees from Alcon Laboratories, Inc. None of the other authors has a financial or proprietary interest in any material or method mentioned.

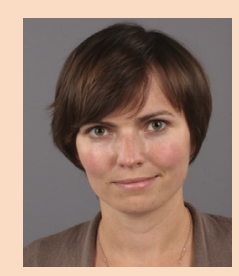

First author:

Natalia Y. Makhotkina, MD

University Eye Clinic, Maastricht University Medical Centre, Maastricht, the Netherlands 